\title{
Influences of Centella Asiatica and Curcuma Longa on Arterial Stiffness in a Hypertensive Animal Model
}

\author{
Patonah Hasimun*, Yani Mulyani, Adinda R Setiawan
}

Departement of Pharmacology and Clinical Pharmacy, Bhakti Kencana University, Jl. R.E. Martadinata No.142, Cipedes, Kec. Cipedes, Kab. Tasikmalaya, Jawa Barat 46133

\begin{tabular}{|c|c|}
\hline Info Article & ABSTRACT \\
\hline Submitted: $05-08-2021$ & There is a strong relationship between arterial stiffness and high blood \\
\hline Revised: $04-10-2021$ & pressure. Arterial stiffness increases the risk of a cardiovascular event and \\
\hline Accepted: $16-12-2021$ & sudden death, especially in hypertensive patients. This study aimed to \\
\hline${ }^{*}$ Corresponding author & determine the effective combination of Centella asiatica and Curcuma longa \\
\hline $\begin{array}{l}\text { Corresponaing author } \\
\text { Patonah Hasimun }\end{array}$ & $\begin{array}{l}\text { on arterial stiffness in hypertensive animal models. Twenty-five male rats } \\
\text { aged 2-3 months were randomly into five groups. The groups comprising the }\end{array}$ \\
\hline Email & negative control and positive control group (receiving drug carriers), the test \\
\hline blku.ac.id & drug group receiving captopril $2.5 \mathrm{mg} / \mathrm{kg}$, the combination of Centella asiatica \\
\hline & control group, all groups received a high-fat diet and $25 \%$ fructose drinking \\
\hline & $\begin{array}{l}\text { water for } 28 \text { days. On day } 15 \text {, they received test drug. On days } 0,14 \text {, and } 28 \text {, } \\
\text { systolic and diastolic blood pressures, as well as the PWV (pulse wave }\end{array}$ \\
\hline & velocity), were assessed. Nitric oxide levels in serum were measured using \\
\hline & Griess reagents on day 28 . The results showed that a combination of CA and \\
\hline & CL doses of 50 and $100 \mathrm{mg} / \mathrm{kg}$ reduced systolic and diastolic blood pressure \\
\hline & accompanied by a decrease in PWV and a statistically significant increase in \\
\hline & $\begin{array}{l}\text { serum NO levels }(\mathrm{p}<0.05) \text {. It concluded that a combination of CA and CL has } \\
\text { the potential as antihypertensive, improving arterial elasticity. }\end{array}$ \\
\hline & Keywords: Arterial stiffness, Centella asiatica, Curcuma longa, Hypertension \\
\hline
\end{tabular}

\section{INTRODUCTION}

Hypertension is inextricably linked to artery stiffness. The flexibility of arteries declines with aging. Aging-related arterial stiffness increases the velocity at which the pressure pulse travels through the aorta, resulting in elevated blood pressure (Sun, 2015). Hypertension is defined as an increase in both systolic and diastolic blood pressure that exceeds normal limits. Uncontrolled increase in blood pressure will cause endothelial dysfunction in several ways, such as increased endothelial cell permeability, which will cause edema and decreased bioavailability of Nitric Oxide (NO) (Wilkinson \& Cockcroft, 2007).

Excessive arterial stiffness puts target organs such as the arteries, heart, and kidneys at risk of injury. It is well established that arterial stiffness is a significant independent risk factor for cardiovascular disease. Increased pulse wave velocity (PWV) by one $\mathrm{m} / \mathrm{s}$ corresponds to increased cardiovascular events by $14 \%$ and allcause mortality by 15\% (Aroor et al., 2013). The strong association between arterial stiffness and hypertension necessitates improved medication since decreased arterial stiffness is required in conjunction with lowering blood pressure. The drug's inability to restore arterial flexibility may account for its failure to treat hypertension. Recent research has demonstrated the critical role of hypertension management in reducing arterial stiffness. Increased nitric oxide levels can increase arterial flexibility and serve as vasodilators (Sharman et al., 2017).

Vascular assessment is critical to achieving successful treatment of hypertension. It can be measured using the PWV technique, which is determined by blood pressure and age. Also, it is believed that heart rate has an independent effect on PWV. Increased heart rate can increase arterial stiffness via changes in smooth muscle tone in large arteries, which influence sympathetic activity. (Tan et al., 2016). However, the relationship between heart rate and PWV is still unknown.

Clinically, PWV assessment is beneficial for predicting and measuring cardiovascular risk in the general population, the elderly, and hypertensive 
patients. A rise in arterial stiffness is associated with endothelial dysfunction (Jadhav \& Kadam, 2005). Previous research has shown that the PVW approach can be used to estimate vascular stiffness in rats. There was a significant difference in PWV values among rats of different ages. This approach could be used to discover natural products that can act as antihypertensive medications while also decreasing arterial stiffness (Zakaria \& Hasimun, 2017a).

Natural medicines that have been beneficial as antihypertensives include Centella asiatica leaves and Curcuma longa rhizome. The content of active compounds, including flavonoids, alkaloids, and saponins, is responsible for pharmacological effects. As the main component in the turmeric rhizome, curcumin has been reported to have various pharmacological activities, including vascular repair. Curcumin has been reported to have antihypertensive activity. Moreover, curcumin improving endothelial function, arterial elasticity, and nitric oxide bioavailability (Cicero et al., 2017). The flavonoid content of Centella asiatica has been reported to reduce blood pressure, cleanse the blood and heal wounds. Also, the flavonoids of Centella asiatica can inhibit the ACE enzyme resulting in a decrease in blood pressure, in-vitro (Sanctis et al., 2001). However, their effects on arterial stiffness are not yet known.

A previous study reported that the combination of Centella asiatica and Curcuma longa in the form of fresh juice preparations could prevent high blood pressure and maintain arterial elasticity in vivo (Hasimun, Mulyani, Sulaeman, \& Saraswati, 2019). Centella asiatica and Curcuma longa can be produced into herbal medicines that effectively lower blood pressure and reduce arterial stiffness in hypertensive patients, based on the results of previous studies. It can prevent complications of cardiovascular disease. This study aimed to determine the effect of Centella asiatica leaves and Curcuma longa rhizome in extract combination against arterial stiffness in hypertensive animal models induced by a high-fat diet and 25\% fructose in drinking water.

\section{MATERIAL AND METHODS}

\section{Plants material authentication}

The leaves of Centella asiatica and the rhizome of Curcuma longa were collected at Manoko Plantation in Lembang, Bandung, Indonesia. Authentication was conducted at the Biological Laboratory, School of Biological Science and Technology, Bandung Institute of Technology
(Registered \#5234/I1.C02.2/PL/2018 as Centella asiatica and \#5948/I1.C02.2/PL/2018 as Curcuma longa). Phytochemistry screening was conducted to determine the secondary metabolites, including alkaloids, flavonoids, saponins, tannins, and steroids-triterpenoids.

\section{Extracts preparation}

Centella asiatica and Curcuma longa were sifted and cleaned of contaminants under running water before being cut into small pieces and dried in the oven at $37^{\circ} \mathrm{C}$. The dried substances were pulverized using a blender. The powder was macerated by immersing it in $70 \%$ ethanol solvent in the extraction chamber for three days in a room protected from light. The obtained filtrate was filtered and dried using a rotary evaporator at $40^{\circ} \mathrm{C}$.

\section{Preparation of High-fat and high-fructose diet (HFHF)}

The high-fat feed consisted of $60 \%$ of standard meals (Pokphan C551®) purchased from local stores and $40 \%$ fat. The fat contained $90 \mathrm{~g}$ duck eggs, $155 \mathrm{~g}$ margarine, and $155 \mathrm{~g}$ beef fat. All ingredients are mixed until homogeneous, ground, and cut to a $2-3 \mathrm{~cm}$ length, then dried in the oven at $37^{\circ} \mathrm{C}$. Fructose solution $25 \%$ in drinking water was prepared every day. All groups except the normal group received a high-fat diet and 25\% fructose drinking water for 28 days.

\section{Animals protocol}

The 2-3-month-old Wistar male rats weighed 200-250g and were housed in an animal laboratory under standard conditions, which included a temperature range of $24-26^{\circ} \mathrm{C}$, a humidity level of $70-75 \%$, and a 12 -hour light-dark cycle. The test animals were fed regularly and given access to drinking water (ad libitum) daily. All procedures followed the ethics and rules for the use and care of animals. The Faculty of Medicine, Padjadjaran University, Bandung, issued ethical approval with registration number 0219030390.

The study refers to previous studies that reported antihypertensive effects of a combination of Curcuma longa and Centella asiatica in juice preparations with a ratio of $1: 1$ (Hasimun, et al., 2019). The study of antihypertensive activity was conducted in-vivo for 28 days in male Wistar rats induced by a high-fat diet and 15\% fructose drinking water. This method refers to the results of previous studies that induction a high-fat diet and drinking containing 25\% fructose for 28 days 
showed animal models of hypertension accompanied by arterial stiffness (Hasimun et al., 2020). A total of 25 male rats aged 2-3 months were grouped randomly into five groups. The groups consisted of the control and induced group (receiving drug carriers), the test drug groups including captopril $2.5 \mathrm{mg} / \mathrm{kg}$, extract combination (1:1) of Centella asiatica (CA) and extract of Curcuma longa (CL) doses of 50 and $100 \mathrm{mg} / \mathrm{kg}$. Except for the control group, all groups were fed a high-fat diet and drinking containing $25 \%$ fructose for 28 days. On day 15, the test drug was administered. Systolic and diastolic blood pressures were taken non-invasively on days 0,14 , and 28 using the CODA tail-cuff device.

On days 0,14 , and 28 , arterial stiffness was determined using the previously described PWV (pulse wave velocity) method (Zakaria \& Hasimun, 2017b). Increased PWV values indicate an increase in arterial stiffness. The electrocardiogram (ECG) sensor and a photoplethysmogram were used as the basis for this PWV measurement method (PPG). Electrocardiograms were used to obtain a signal from the electrical activity of the heart muscle by attaching electrodes to the right palm, left palm, and right foot. Simultaneously, a PPG sensor was placed at the base of the tail to monitor blood flow changes.

In summary, the ECG determined the potential difference between the left and right arms by using the right leg as a common reference point. The difference in potential induced by cardiac muscle contraction. The peak of the electrocardiogram (ECG) signal (R-wave) was utilized as a reference time point to indicate when the ventricle contracts to push blood away from the heart. The PPG sensor was positioned at the tail base to determine the change in blood volume. The foot of the PPG signal was applied as a second-time reference point to determine the arrival time of the heart-pumped blood.

Nitric oxide serum levels were measured by previously reported methods with a slight modification (Garmana et al., 2018). On the 28th day, blood was drawn from all groups of animals. Blood centrifugation separated the serum at a speed of 10,000 rpm for $10 \mathrm{~min}$. Deproteination of $400 \mu \mathrm{L}$ serum was got with $6 \% \mathrm{ZnSO} 4$ of $80 \mu \mathrm{L}$ then centrifuged. The supernatant was reacted with $80 \mu \mathrm{L}$ Cadmium $6 \%$ for $15 \mathrm{~min}$. The $380 \mu \mathrm{L}$ of this solution was added with $1.5 \mathrm{~mL}$ of Griess reagent, then incubated for $1 \mathrm{~h}$. UV Vis spectrophotometry measured absorbance at a $535 \mathrm{~nm}$ wavelength.

\section{Analytical Data}

The data obtained are displayed in tables and figures as the average value and standard deviation of 5 observational data for each group. Statistical significance between the groups was analyzed by a one-way ANOVA test using the SPSS 18.0 software. A statistically significant as indicated by $\mathrm{p}<0.05$.

\section{RESULT AND DISCUSSION}

Extract yield was $16.98 \%$ and $10 \%$ for CA and CL, respectively. The results are following the Indonesian Herbal Pharmacopoeia that the yield of Centella asiatica extract is not less than $7.3 \%$ while for Curcuma longa not less than $11 \%$. Phytochemical screening identified flavonoids, saponins, tannins, and steroid-triterpenoids in CA, while the flavonoid, saponins, and steroidsterpenoids in CL. These results were in line with previous studies that Centella asiatica leaves contain phenolic compounds with antioxidant activity (Zainol et al., 2003). The different solvents used in Centella asiatica extraction produce different amounts of phenolic compounds. The solvent's polarity affected the content of extracted phenolic compounds, which was proportionate to their antioxidant and antibacterial activities. Centella asiatica extracted by ethanol solvent produced the highest phenolic compound content compared to other solvents (Yasurin et al., 2016). Season differences when harvesting Centella asiatica determines the yield of its bioactive compounds. In summer (most sun exposure), the plant produces the highest terpenoids, flavonoids, and chlorogenic acid (Alqahtani et al., 2015).

The pharmacological activity of Curcuma species is related to the presence of curcumin compounds as bioactive compounds. As one species of Curcuma, turmeric (Curcuma longa) is reported to have the highest curcumin content than other Curcuma species (Hunter, 2018). Therefore turmeric is very potential to be developed as a drug to overcome various diseases, including hypertension.

\section{Evaluation of Systolic Blood Pressure}

This study showed a significant difference in the induced group's systolic blood pressure on day $28(\mathrm{p}<0.05)$ compared to the control group. High fat and fructose diet (HFHF) for 28 days doubled the systolic blood pressure compared to the negative control group (Figure 1). 


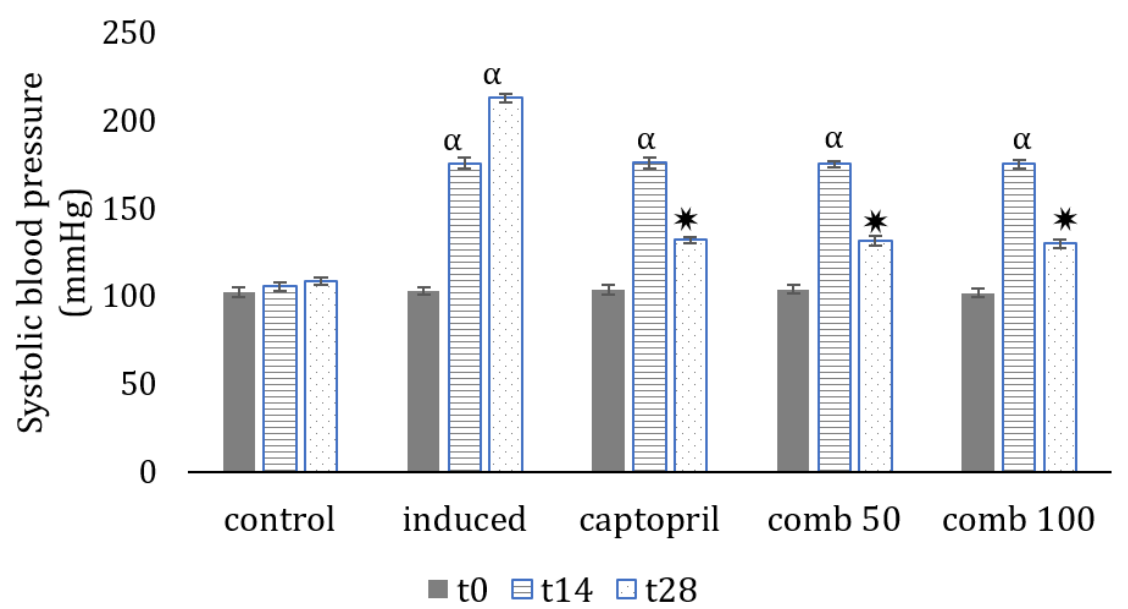

Figure 1. The systolic blood pressure on day $0,14,28$ after treatment compared to baseline; comb 50 (CACL-combined dose of $50 \mathrm{mg} / \mathrm{kg}$ ), comb 100 (CA-CL-combined dose of $100 \mathrm{mg} / \mathrm{kg}$ ); CA (extract of Centella asiatica), CL (extract of Curcuma longa).

$\alpha$ There was a significant difference compared to the control group $(\mathrm{p}<0.05)$; * There was a significant difference compared to the induced group $(\mathrm{p}<0.05)$

Table I. The percentage increased in body weight, heart rate, angle of QRS-T, as well as a serum level of nitric oxide on day 28 after treatment.

\begin{tabular}{ccccc}
\hline Treatment group & Bodyweight (\%) & Heart rate (beat/min) & QRS-T (o) & Nitric oxide level $(\boldsymbol{\mu M})$ \\
\hline Control & $14 \pm 4.1$ & $371 \pm 2.5$ & $87 \pm 2.9$ & $153 \pm 5^{*}$ \\
Induced & $27 \pm 4.0$ & $656 \pm 2.1$ & $120 \pm 1.0$ & $2 \pm 1$ \\
Captopril & $18 \pm 4.4^{*}$ & $450 \pm 2.1^{*}$ & $115 \pm 1.3^{*}$ & $34 \pm 1^{*}$ \\
Comb 50 & $17 \pm 4.1^{*}$ & $450 \pm 1.0^{*}$ & $110 \pm 1.5^{*}$ & $64 \pm 1^{*}$ \\
Comb 100 & $16 \pm 4.4^{*}$ & $447 \pm 1.7^{*}$ & $103 \pm 2.0^{* \alpha}$ & $109 \pm 1^{*}$ \\
\hline
\end{tabular}

$\alpha=$ There was a significant difference compared to the control group $(\mathrm{p}<0.05)$; $*=$ There was a significant difference compared to the induced group ( $\mathrm{p}<0.05$ ); comb 50 (CA-CL-combined dose of $50 \mathrm{mg} / \mathrm{kg}$ ), comb 100 (CA-CL-combined dose of $100 \mathrm{mg} / \mathrm{kg}$ ); CA (extract of Centella asiatica), CL (extract of Curcuma longa)

It has been reported that a high fat and fructose diet for an extended time causes metabolic disorders characterized by hypertension and cardiovascular remodeling. The HFHF diet stimulates sympathetic nerve activity, raising blood pressure (Hwang et al., 1987). Cardiovascular remodeling due to the fructose diet is characterized by increased systolic blood pressure, endothelial dysfunction, increased arterial stiffness and left ventricular cardiac repolarization (Panchal et al., 2011).

The current study demonstrated that a 28day HFHF diet increased body weight by more than $20 \%$, indicating obesity (Table 1). It is thought that prolonged fructose diet-induced leptin resistance is a cause of obesity. Thus, consuming a high-fat diet while developing leptin resistance accelerates the onset of obesity (Shapiro et al., 2008). In contrast, the group that received a combination of CA and CL for 14 days showed a bodyweight reduction compared to the control group (Table I).

The present study showed a positive correlation between obesity and arterial stiffness (Figure 3). These results were in line with a previous study that obesity increases the risk of cardiovascular disease by affecting heart and blood vessel function. In obesity, metabolic requirements increase, leading to an increase in total blood volume and cardiac output. The heart's workload is more significant in obese subjects. Also, obesity raises the risk of vascular damage, including endothelial dysfunction, leading to decreased nitric oxide production (NO). 


\section{Patonah Hasimun}

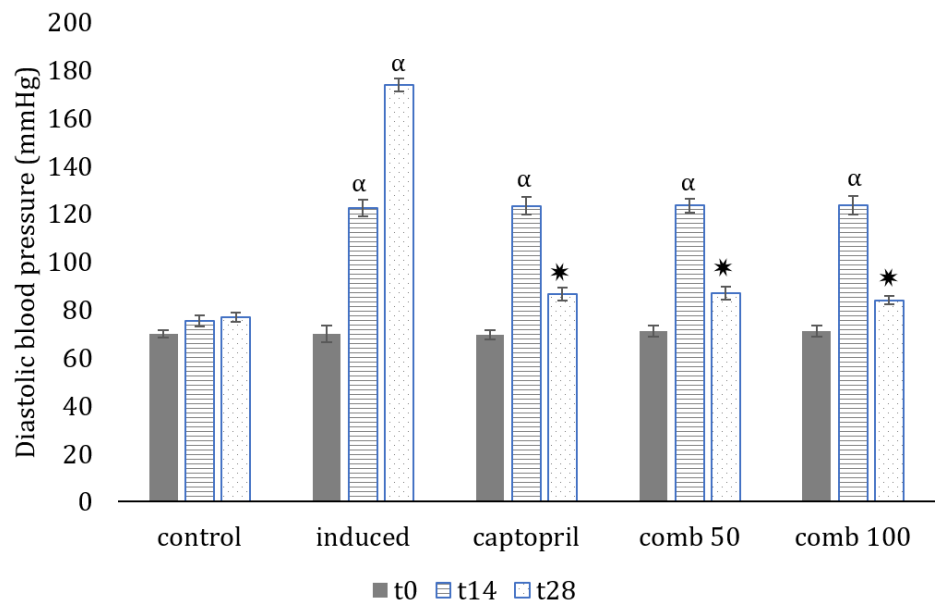

Figure 2. The diastolic blood pressure on day 0,14, 28 after treatment compared to baseline; comb 50 (CACL-combined dose of $50 \mathrm{mg} / \mathrm{kg}$ ), comb 100 (CA-CL-combined dose of $100 \mathrm{mg} / \mathrm{kg}$ ); CA (extract of Centella asiatica), CL (extract of Curcuma longa)

$\alpha$ There was a significant difference compared to the control group $(\mathrm{p}<0.05)$; * There was a significant difference compared to the induced group $(\mathrm{p}<0.05)$

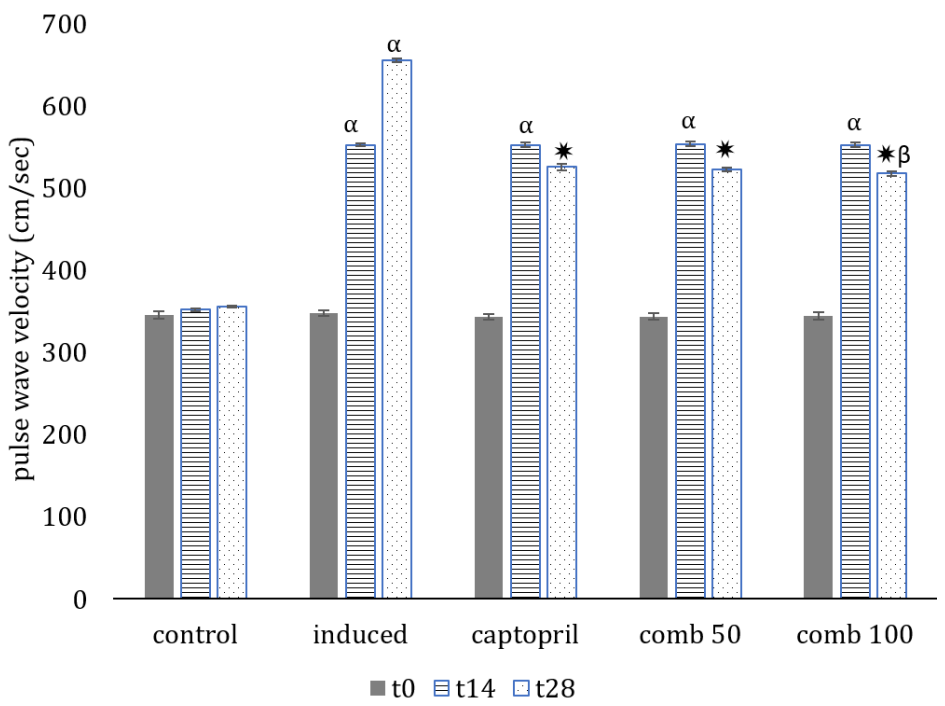

Figure 3. The pulse wave velocity (PWV) on day 0,14, 28 after treatment compared to baseline; comb 50 (CA-CL-combined dose of $50 \mathrm{mg} / \mathrm{kg}$ ), comb 100 (CA-CL-combined dose of $100 \mathrm{mg} / \mathrm{kg}$ ); CA (extract of Centella asiatica), CL (extract of Curcuma longa)

$\alpha$ There was a significant difference compared to the control group $(\mathrm{p}<0.05)$; * There was a significant difference compared to the induced group $(\mathrm{p}<0.05) ; \beta$ There was a significant difference compared to the captopril group $(\mathrm{p}<0.05)$

Furthermore, it causes vasoconstriction and increased peripheral resistance resulting in hypertension. As a result, weight loss initiatives reduce the risk of cardiovascular events (Poirier et al., 2006). The CA and CL can reduce systolic blood pressure, which was statistically significant compared to the induced group $(\mathrm{p}<0.05)$. The group that received a combination of CA and CL showed decreased blood pressure accompanied by reduced body weight (Table I). This finding demonstrates that weight loss affects blood pressure reduction.

Asiaticoside acid, the primary constituent of Centella asiatica, exhibits antiobesity effects and 
acts similarly to orlistat in weight loss, insulin resistance, and gamma-PPAR receptor regulation. The antiobesity effects are mediated by modulating the activity of the PPAR-gamma receptor and its target genes, which are involved in lipid metabolism regulation (Uddandrao et al., 2019). Curcuminoid, the primary substance in Curcuma longa, has also been shown to decrease leptin levels in the blood, suggesting that it may work as an appetite suppressant (Atkin et al., 2017).

\section{Evaluation of Diastolic Blood Pressure}

Diastolic blood pressure refers to the pressure in the arteries when the heart muscle relaxes(Atkin et al., 2017). It presented data of diastolic blood pressure during the treatment in Figure 2. The present study showed that the HFHF diet increased diastolic blood pressure more than twice that of the control group.

It was established that a high fructose diet increases diastolic blood pressure through the heart's left ventricular remodeling process.. The fructose diet is associated with renal and systemic hemodynamic abnormalities. It may cause aortic stiffness due to decreased NO levels in the kidneys and fluid retention in the renal tubules (Komnenov et al., 2018).

On the 28th day, the group receiving a combination of CA and CL showed a decrease in diastolic blood pressure that was statistically significant $(p<0.05)$ compared to the induced group. Its effect was comparable to captopril as a reference drug (Figure 2).

\section{Evaluation of pulse wave velocity (PWV)}

The present study showed, the group that received the HFHF diet for 28 days showed a twofold increase in arterial stiffness (PWV) compared to the control group. On day 28 , however, the group receiving a combination of CA and CL reduced arterial stiffness significantly more than the induced group (Figure 3). The authors discovered a strong link between increased systolic and diastolic blood pressure and increased arterial stiffness.

The fructose diet stimulated the RAAS system (renin-angiotensin-aldosterone system), resulting in arterial stiffness due to reduced nitric oxide bioavailability. Thus, treatments that block RAAS, such as ACE inhibitors, have shown higher efficacy when compared to other antihypertensive medication groups (Jia et al., 2018).

Figure 3 demonstrated the improvement in arterial flexibility during the 28-day treatment. Groups that received a combination of $\mathrm{CL}$ and CA dose of $50 \mathrm{mg} / \mathrm{kg}$ showed a decrease in arterial stiffness comparable to captopril.

The arterial stiffness assessment is a valuable technique for managing hypertension, particularly resistant hypertension, risk stratification of cardiovascular complications. The primary strategies for managing arterial stiffness in patients at high cardiovascular risk are to address modifiable risk factors, such as obesity and hypertension (Wu et al., 2015).

The current study reinforces the antihypertensive properties of Centella asiatica and Curcuma longa. It enhances endothelial function by increasing the bioavailability of nitric oxide and improving arterial flexibility. The present study demonstrates that the combination of Centella asiatica and Curcuma longa has a synergistic antihypertensive impact and may help prevent cardiovascular disease through vascular repair. The results on this study corroborate previous reports of antihypertensive and anti-arterial stiffness in the combination of Centella asiatica and Curcuma longa in fresh juice preparations (Hasimun, et al., 2019). The pharmacological effects of ethanol extract from Centella asiatica and Curcuma longa are greater than those of water extracts. It is related to the content of flavonoids as bioactive compounds (Barbosa \& Minguillan, 2021; Quyen et al., 2020)

\section{Evaluation of NO Levels in Blood}

Nitric oxide (NO) is a molecule required to transfer electrical signals within cells. Nitric oxide is primarily synthesized in the endothelium of blood vessels, where it is formed by the enzyme eNOS metabolizing L-arginine (endothelial nitric oxide synthetase). Then, the generated NO stimulates guanylyl cyclase, resulting in the formation of 3, 5-cyclic guanosine monophosphate (cGMP). It causes vasodilation of the vascular smooth muscle, inhibits platelet aggregation, and has anti-inflammatory, anti-proliferative, and antimigratory actions on leukocytes, endothelial cells, and vascular smooth muscle cells. As a result, it protects against atherosclerosis (Hermann et al., 2006). It is well established that arterial stiffness is caused by a decline in endothelial function, decreasing nitric oxide levels. Numerous studies indicate that reductions in blood pressure are associated with enhanced nitric oxide generation via improved endothelial function (Nicoll \& Henein, 2018). 
The present study established that the HFHF diet resulted in metabolic disorders. It is defined by elevated systolic and diastolic blood pressures and arterial stiffness caused by endothelial dysfunction, as indicated by decreased NO serum levels. The group that received a combination of CA and CL showed an increase in NO serum levels. The combination of CA and CL works synergistically in increasing serum NO levels (Table 1). The group that received its combination dose of $100 \mathrm{mg} / \mathrm{kg}$ showed a high vasodilation effect due to the highest nitric oxide serum level.

Captopril has been shown to protect against cardiovascular disease by increasing the bioavailability of NO. Captopril enhances Nitric Oxide's bioavailability by inhibiting the Angiotensin-Converting Enzyme (Pechanova et al., 2006). Curcumin is believed to improve vascular function through its effect on NO bioavailability. Curcumin treatment was found to significantly improve endothelial function and arterial flexibility in diabetic patients and obesity. A recent study has revealed curcumin's benefits for vascular health, particularly in patients with cardiovascular risk factors (Campbell \& Fleenor, 2017).

\section{Evaluation heart rate and QRS-T angle related to hypertension}

The present study showed that the induced group experienced increased heart rate and increased systolic and diastolic blood pressure. The combination of CA and CL extracts resulted in a decrease in systolic and diastolic blood pressure, as well as in heart rate and QRS-T angle (Table 1). There is strong evidence that the autonomic nervous system is critical in blood pressure regulation (Mancia et al., 2013). Blood pressure elevation is strongly associated with heart rate (Palatini \& Julius, 2004). Chronic essential hypertension appears to be related to cardiac autonomic control dysfunction(Mussalo et al., 2001). Additionally, it has been reported that hypertension causes a widening of the QRS-T angle, raising the risk of cardiovascular events.

\section{CONCLUSION}

The 28-day diet causes obesity and endothelial dysfunction as risk factors for cardiovascular disease. Combining Centella asiatica with Curcuma longa extracts results in a synergistic effect on arterial stiffness. Additional research is necessary to define the cut-off threshold for initiating combination therapy.

\section{ACKNOWLEDGEMENT}

We thank the Ministry of Research, Technology, and Higher Education of Indonesia for funding this research under the Basic Research Grant number: 065 /SP2H/LT/DRPM/2021.

\section{REFERENCES}

Alqahtani, A., Tongkao-on, W., Li, K. M., RazmovskiNaumovski, V., Chan, K., \& Li, G. Q. 2015. Seasonal variation of triterpenes and phenolic compounds in Australian Centella asiatica (L.) Urb. Phytochemical Analysis, 26(6), 436-443.

Aroor, A., DeMarco, V., Jia, G., Sun, Z., Nistala, R., Meininger, G., \& Sowers, J. 2013. The Role of Tissue Renin-Angiotensin-Aldosterone System in the Development of Endothelial Dysfunction and Arterial Stiffness . In Frontiers in Endocrinology (Vol. 4, p. 161).

Atkin, S. L., Katsiki, N., Derosa, G., Maffioli, P., \& Sahebkar, A. 2017. Curcuminoids lower plasma leptin concentrations: A metaanalysis. Phytotherapy Research, 31(12), 1836-1841.

Barbosa, G. B., \& Minguillan, J. M. O. 2021. Antioxidant activity and total phenolic content of fresh and cured rhizomes of Curcuma longa and Etlingera philippinensis. International Food Research Journal, 28(4), 839-847.

Campbell, M. S., \& Fleenor, B. S. 2017. The emerging role of curcumin for improving vascular dysfunction: A review. Critical Reviews in Food Science and Nutrition, 1-10.

Cicero, A. F. G., Fogacci, F., \& Colletti, A. 2017. Food and plant bioactives for reducing cardiometabolic disease risk: an evidence based approach. Food \& Function, 8(6), 2076-2088.

De Sanctis, M. T., Belcaro, G., Incandela, L., Cesarone, M. R., Griffin, M., Ippolito, E., \& Cacchio, M. 2001. Treatment of edema and increased capillary filtration in venous hypertension with total triterpenic fraction of Centella asiatica: a clinical, prospective, placebo-controlled, randomized, doseranging trial. Angiology, 52(2_suppl), S55S59.

Garmana, A. N., Sukandar, E. Y., \& Fidrianny, I. 2018. Antihypertension study of anredera cordifolia (ten). V. Steenis extract and its fractions in rats through dexamethasone 
induction and nitric oxide release. Asian $J$ Pharm Clin Res, 1, 278-282.

Hasimun, P., Mulyani, Y., Rehulina, E., \& Zakaria, H. 2020. Impact of Black Garlic on Biomarkers of Arterial Stiffness and Frontal QRS-T Angle on Hypertensive Animal Model. Journal of Young Pharmacists, 12(4), 338-342.

Hasimun, P., Mulyani, Y., Sulaeman, A., \& Embas Sara, D. A. 2019. Prevention of Hypertension and Arterial Stiffness by Combination of Centella asiatica and Curcuma longa in Rats. Asian Journal of Biological Sciences, 12(2), 173-179.

Hermann, M., Flammer, A., \& Lüscher, T. F. 2006. Nitric oxide in hypertension. Journal of Clinical Hypertension (Greenwich, Conn.), 8(12 Suppl 4), 17-29.

Hunter, K. 2018. Evaluation of the Variation in Growth, Rhizome Yield and RhizomePhytochemical Content among Turmeric (Curcuma Species) GenotypesGrown in North Alabama. Alabama Agricultural and Mechanical University.

Hwang, I.-S., Ho, H., Hoffman, B. B., \& Reaven, G. M. 1987. Fructose-induced insulin resistance and hypertension in rats. Hypertension, 10(5), 512-516.

Jadhav, U. M., \& Kadam, N. N. 2005. Non-invasive assessment of arterial stiffness by pulsewave velocity correlates with endothelial dysfunction. Indian Heart Journal, 57(3), 226-232.

Jia, G., Aroor, A. R., Martinez-Lemus, L. A., \& Sowers, J. R. 2018. Potential role of antihypertensive medications in preventing excessive arterial stiffening. Current Hypertension Reports, 20(9), 76.

Komnenov, D., Gaudette, J., Zenner, Z., Chen, H., \& Rossi, N. 2018. Fructose-induced saltsensitive hypertension increases aortic stiffness and induces changes in systemic and renal hemodynamics. The FASEB Journal, 32(1_supplement), 714-715.

Mancia, G., Fagard, R., Narkiewicz, K., Redon, J., Zanchetti, A., Böhm, M., Christiaens, T., Cifkova, R., de Backer, G., \& Dominiczak, A. 2013. $2013 \mathrm{ESH} / \mathrm{ESC}$ guidelines for the management of arterial hypertension: the Task Force for the Management of Arterial Hypertension of the European Society of Hypertension (ESH) and of the European Society of Cardiology (ESC). Blood Pressure, 22(4), 193-278.
Mussalo, H., Vanninen, E., Ikäheimo, R., Laitinen, T., Laakso, M., Länsimies, E., \& Hartikainen, J. 2001. Heart rate variability and its determinants in patients with severe or mild essential hypertension. Clinical Physiology, 21(5), 594-604

Nicoll, R., \& Henein, M. Y. 2018. Caloric restriction and its effect on blood pressure, heart rate variability and arterial stiffness and dilatation: a review of the evidence. International Journal of Molecular Sciences, 19(3), 751.

Palatini, P., \& Julius, S. 2004. Elevated heart rate: a major risk factor for cardiovascular disease. Clinical and Experimental Hypertension, 26(7-8), 637-644.

Panchal, S. K., Poudyal, H., Iyer, A., Nazer, R., Alam, A., Diwan, V., Kauter, K., Sernia, C., Campbell, F., Ward, L., Gobe, G., Fenning, A., \& Brown, L. 2011. High-carbohydrate High-fat Dietinduced Metabolic Syndrome and Cardiovascular Remodeling in Rats. Journal of Cardiovascular Pharmacology, 57(1).

Pechanova, O., Matuskova, J., Capikova, D., Jendekova, L., Paulis, L., \& Simko, F. 2006. Effect of spironolactone and captopril on nitric oxide and S-nitrosothiol formation in kidney of L-NAME-treated rats. Kidney International, 70(1), 170-176.

Poirier, P., Giles, T. D., Bray, G. A., Hong, Y., Stern, J. S., Pi-Sunyer, F. X., \& Eckel, R. H. 2006. Obesity and cardiovascular disease: pathophysiology, evaluation, and effect of weight loss: an update of the 1997 American Heart Association Scientific Statement on Obesity and Heart Disease from the Obesity Committee of the Council on Nutrition, Physical. Circulation, 113(6), 898-918.

Quyen, N. T. C., Quyen, N. T. N., Quy, N. N., \& Quan, P. M. 2020. Evaluation of total polyphenol content, total flavonoid content, and antioxidant activity of Centella asiatica. IOP Conference Series: Materials Science and Engineering, 991(1), 12020.

Shapiro, A., Mu, W., Roncal, C., Cheng, K.-Y., Johnson, R. J., \& Scarpace, P. J. 2008. Fructose-induced leptin resistance exacerbates weight gain in response to subsequent high-fat feeding. American Journal of Physiology-Regulatory, Integrative and Comparative Physiology, 295(5), R1370-R1375.

Sharman, J. E., Boutouyrie, P., \& Laurent, S. 2017. Arterial (aortic) stiffness in patients with resistant hypertension: from assessment to 
treatment. Current Hypertension Reports, 19(1), 2.

Sun, Z. 2015. Aging, arterial stiffness, and hypertension. Hypertension, 65(2), 252-256.

Tan, I., Spronck, B., Kiat, H., Barin, E., Reesink, K. D., Delhaas, T., Avolio, A. P., \& Butlin, M. 2016. Heart rate dependency of large artery stiffness. Hypertension, 68(1), 236-242.

Uddandrao, V. V.S., Rameshreddy, P., Brahmanaidu, P., Ponnusamy, P., Balakrishnan, S., Ramavat, R. N., Swapna, K., Pothani, S., Nemani, H., \& Meriga, B. 2019. Antiobesity efficacy of asiatic acid: down-regulation of adipogenic and inflammatory processes in high fat diet induced obese rats. Archives of Physiology and Biochemistry, 1-10.

Wilkinson, I., \& Cockcroft, J. R. 2007. Cholesterol, lipids and arterial stiffness. In Atherosclerosis, Large Arteries and Cardiovascular Risk (Vol. 44, pp. 261-277). Karger Publishers.

Wu, C.-F., Liu, P.-Y., Wu, T.-J., Hung, Y., Yang, S.-P., \& Lin, G.-M. 2015. Therapeutic modification of arterial stiffness: an update and comprehensive review. World Journal of Cardiology, 7(11), 742.

Yasurin, P., Sriariyanun, M., \& Phusantisampan, T. 2016. The Bioavailability Activity of Centella asiatica. King Mongkut's University of Technology North Bangkok International Journal of Applied Science and Technology, 9(1), 1-9.

Zainol, M. K., Abd-Hamid, A., Yusof, S., \& Muse, R. 2003. Antioxidative activity and total phenolic compounds of leaf, root and petiole of four accessions of Centella asiatica (L.) Urban. Food Chemistry, 81(4), 575-581.

Zakaria, H., \& Hasimun, P. 2017a. Non-invasive pulse wave velocity measurement in mice. Proceedings - 2017 International Seminar on Sensor, Instrumentation, Measurement and Metrology: Innovation for the Advancement and Competitiveness of the Nation, ISSIMM 2017, 2017-Janua.

Zakaria, H., \& Hasimun, P. 2017b. Non-invasive pulse wave velocity measurement in mice. 2017 International Seminar on Sensors, Instrumentation, Measurement and Metrology (ISSIMM), 95-98. 